\title{
APPLYING DIGITAL TECHNOLOGIES TO TRAINING: A FOCUS ON PICTORIAL COMMUNICATION
}

\section{CONTENTS}

Page

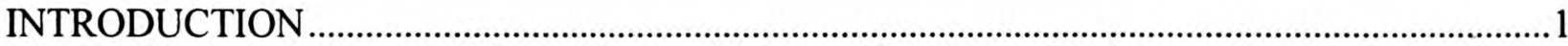

BACKGROUND

The Digital Battlefield..................................................................................................

The Common Picture: A Focus on Pictorial Communication.....................................6

Digital Technologies and Army Training..........................................................................

The Common Picture: Key Lessons Learned from the AWEs.....................................

Learning Theory and Instructional Design ........................................................................9

Army Training Theory and Design .....................................................................9

Contemporary Learning Theory and Design ............................................................10

Theoretical Implications for Digital Training ………………...............................................11

The Worker's Mental Model ...................................................................................11

Microworld Work Models....................................................................................12

Perceptual Focus: Matching Internal and External Models.......................................13

Practical Implications for Digital Training ........................................................................13

Background Summary ....................................................................................................15

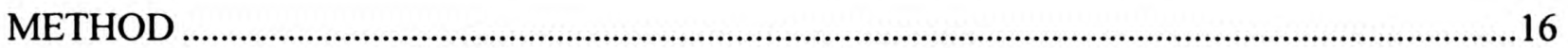

Define the Common Picture ..........................................................................................

Develop a Conceptual Definition: A METT-T Approach.........................................18

Develop an Operational Definition: Bound the Problem …………………………....19

Determine Information Requirements......................................................................23

Assess $C^{4}$ I Information Capabilities.........................................................................28

Assess Performance, Give Feedback ...................................................................29

Communicate the Common Picture....................................................................................33

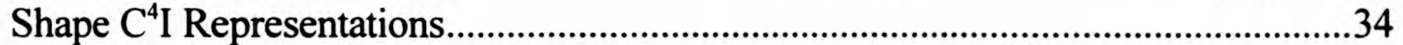

Shape Mental Models .................................................................................................

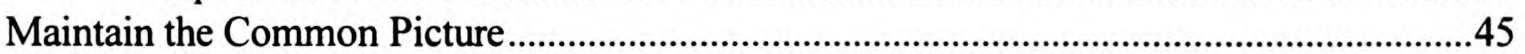

Develop a Communications Model...………………………………………......48

Integrate Digital Technologies …………………………………...........................49

Develop Multi-Level Training ……………………………………………......

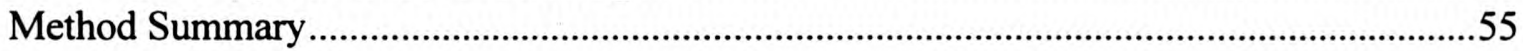

